\title{
Nursing \& Health Care Ethics Related to the COVID-19 Pandemic: Policy Guideline Recommendations Based on UNESCO's Universal Declaration of Bioethics and Human Rights
}

Kristen Jones-Bonofiglio ${ }^{1}$, Miriam Carole Atieno Wagoro ${ }^{2}$, Judie Arulappan ${ }^{3}$, Annabelle Brown $^{4}$, Karen Cassells ${ }^{5}$, Vivienne Cooper ${ }^{6}$, Kathleen A DiGangi Condon ${ }^{7}$, Raya Gurevich-Gal ${ }^{8}$, Rebelee Christy Jeyasingh ${ }^{9}$, S. Ani Grace Kalaimathi ${ }^{10}$, Joy R. Kezia ${ }^{11}$, Sharron Leung ${ }^{12}$, Selva Titus ${ }^{13}$, Joyce Neumann ${ }^{14}$

${ }^{1}$ Director Lakehead University Centre for Health Care Ethics and Head of Unit, International Network of UNESCO Chair in Bioethics, Thunder Bay, Ontario, Canada.

${ }^{2}$ Department of Mental Health, Nurse Specialist and Director, School of Nursing Sciences, Nairobi University, Nairobi, Kenya.

${ }^{3}$ Assistant Professor, Department of Maternal and Child Health, College of Nursing, Sultan Qaboos University, Al Khoudh, Muscat, Sultanate of Oman

${ }^{4}$ Clinical Nurse Facilitator, Holmesglen, Melbourne, Australia

${ }^{5}$ Enhanced Psychogeriatric Resource Consultant, Geriatric Outreach Team, Woodstock Hospital, Woodstock, Ontario, Canada.

${ }^{6}$ Head of Nursing, NHS Wales, United Kingdom.

${ }^{7}$ Nurse Practitioner, Division of Palliative Medicine and Bioethics, NYU Langone Health, Mineola, New York, United States of America.

${ }^{8}$ Health Care Simulation Specialist; Registered Nurse, Emergency Department, Soroka University Medical Center, Beer Sheva, Israel.

${ }^{9}$ Adult Nurse Practitioner, South Florida Inpatient Associates, Davie, Florida, United States of America.

${ }^{10}$ Kalaimathi Registrar, Tamil Nadu Nurses and Midwives Council, Chennai, India.

${ }^{11}$ Nursing Superintendent, Apollo Specialty Hospital, Vanagaram, Chennai, India.

${ }^{12}$ Head of Nursing Education, School of Continuing Education, Hong Kong Baptist University, Kowloon, Hong Kong.

${ }^{13}$ Dean, College of Nursing, Gulf Medical University, Amjan, United Arab Emirates.

${ }^{14}$ Program Director/Advanced Practice Registered Nurse and Adjuvant Ethicist, Sections of Stem Cell Transplantation and Integrated Ethics, MD Anderson Cancer Centre, Houston, Texas, United States of America.

Corresponding Author: Kristen Jones-Bonofiglio

E-mail: Kristen.Jones@lakeheadu.ca

\section{Acknowledgement}

This document was finalized in March 2021 at/near the one year anniversary of the initial declaration of the COVID-19 disease as a pandemic. First identified as 2019 novel coronavirus in China, the severe acute respiratory syndrome coronavirus 2 (SARS-CoV-2) has circled our globe and further mutated along the way. While presenting individuals, teams, organizations, sectors and systems with significant challenges and difficult ethical burdens, it has also resulted in tremendous efforts toward collaboration and solidarity in ways that otherwise may never have been considered or realized. It is the sincere hope of members of the global nurse leaders panel that 
lessons learned from COVID-19 will catalyze much needed changes in health care worldwide and not be simply forgotten. We respectfully honour those who have lost their lives to COVID-19; our family members, friends and loved ones, and colleagues.

\section{UNESCO's Universal Declaration of Bioethics and Human Rights}

In 2005, the United Nations Educational Scientific and Cultural Organization (UNESCO) adopted a Universal Declaration of Bioethics and Human Rights with fifteen core ethical principles. Further, the Declaration provides details about the scope, aims, application of principles, promotion of the declaration, and final provisions [please see https://unesdoc.unesco.org/ark:/48223/pf0000142825.page $=80$ for full text]. The core ethical principles offer guidance and a pragmatic lens for nursing practice and ethical decision-making across many sectors of health care around the world, and include:

- Article 3- Human dignity and human rights

- Article 4- Benefit and harm

- Article 5- Autonomy and individual responsibility

- Article 6- Consent

- Article 7- Persons without capacity to consent

- Article 8- Respect for human vulnerability and personal integrity

- Article 9- Privacy and confidentiality

- Article 10- Equality, justice and equity

- Article 11- Non-discrimination and non-stigmatization

- Article 12- Respect for cultural diversity and pluralism

- Article 13- Solidarity and cooperation

- Article 14- Social responsibility and health

- Article 15- Sharing of benefits

- Article 16- Protecting future generations

- Article 17- Protection of the environment, the biosphere and biodiversity

\section{Additional Ethical Principles to Consider}

Working with a framework of ethical principles, nurses strive to uphold a standard of care that meets professional, legal, and personal moral requirements for responsibility, accountability, and advocacy. While specific aspects of these ethical principles may vary based on social, cultural, and ethnic norms of a given country, the core ethical principles are largely consistent and ought to be adhered to in clinical, educational, and research practices.

- Non-maleficence: Nurses ought to promote and protect decisions and/or actions that will minimize, mitigate, or prevent harm. Risk management and harm reduction with and for the patient is a key responsibility of nurses, however, this includes advocacy for least restrictive and coercive measures.

- Autonomy: Nurses ought to respect and support a person's right to their own decision making process and choices. Respectful attention to and application of known past wishes and desires should be adhered to on behalf of patients who are not competent or capable of decision making. There are generally three conditions that are necessary for autonomy, including full disclosure of information, comprehension of the information, and a voluntary decision that is made without undue influence. Autonomous decision making may be achieved by an individual alone or by an individual with selected collaborators, including community members who may or may not be blood-related or considered to be close family members/kin.

- Justice: Nurses ought to be aware of the social determinants of health and promote fairness through the equal and/or equitable distribution of health burdens and benefits. Nurses ought to understand the barriers to achieving social justice within structures/systems and recognize factors unique to vulnerable and marginalized populations. Further, nurses 
ought to seek knowledge about how the intersection of race, class, gender, and culture relate to health disparities, structural and systemic violence, oppression, and poor health outcomes. Also, justice includes issues of appropriate allocation of the right resources at the right time to patients who need care, in the spirit of proportionality. Even in emergencies, there is a need to deploy the right nurse/provider-to-patient ratio, with the right qualification and experience/expertise to protect and promote patient safety. In clinical research, nurses need to ensure that inclusion and exclusion criteria are justified, even in pandemics [1].

- Beneficence: Nurses ought to promote and protect decisions and actions that will maximize or restore benefits and good health outcomes. Further, nurses ought to promote and protect an individual's right to dignity at all times. In the interpersonal and therapeutic, professional relationship between a patient/client and a nurse, there must be a primary focus on helping and healing the patient. However, nurses often must navigate competing relational obligations to promote beneficence.

- Truthfulness: Nurses ought to seek to uphold a commitment to openness, honesty, integrity, and transparent decision making. Nursing care of the patient/client must be grounded in the best available scientific evidence and professional knowledge. Each patient/client must be cared for as an individual and at a level that seeks to address their needs and interests for further information.

- Trust: Nurses are among the most trusted health care professionals [2] and as such ought to seek to maintain and uphold this principle with patients, families, and communities. The public's trust in nurses is closely woven with an expectation for a high standard of ethical practice and compassionate care.

\section{International Council of Nurses- Code of Ethics}

First established in 1953, the International Council of Nurses' (ICN) Code of Ethics acts as a supranational model for ethical standards in nursing practice [3]. The latest version of the revised code (ICN, 2012), highlights four core nursing responsibilities [4]:

- Promote health

- Prevent illness

- Restore health

- Alleviate suffering

The ICN's code of ethics (2012) indicates that nurses must advocate for the human rights of patients, families, and communities. Therefore, nurses must work to address social issues through their practice in systems and within interdisciplinary teams. The ICN's code is currently under revision and it is expected to have a number of key additions, namely, the inclusions of nursing duties and obligations for challenging unethical behaviours and considerations for impacts to nursing related to technology, digital communications, and artificial intelligence [3]. An inprogress draft of the ICN's most current suggested revisions to the code of ethics for nurses is available online (https://www.icn.ch/system/files/documents/202010/CoE_Version\%20for\%20Consultation_October\%202020_EN.pdf ).

\section{UNESCO's Chair in Bioethics Education Department's Global Nurse Leaders Panel: National Codes of Ethics for Nurses}

Australia: Australian College of Nursing/Australian Nursing Federation/Nursing and Midwifery Board of Australia, Code of Ethics for Nurses in Australia (2002; pp. 1-11) https://waubrafoundation.org.au/wp-content/uploads/2015/05/New-Code-of-Ethics-forNurses-August-2008.pdf

Canada: Canadian Nurses Association (CNA), Code of Ethics for Registered Nurses (2017; pp. 1-60) https://cna-aiic.ca/en/nursing-practice/nursing-ethics 
India: Andhra Pradesh Nursing Council (APNMC), Code of Ethics for Nurses in India (n.d.; pp. 1-5) http://hmis.ap.nic.in/APNMC/pdfs/ethics.pdf

Israel: Israeli Nurses Federation - Ethic Division, The Ethics Code of the Israeli Nurses (2018; pp. 115) https://www1.health.gov.il/nursing/work/toolkits/code-of-ethics/

Hong Kong: The Nursing Council of Hong Kong, Code of Ethics and Professional Conduct for the Nurses in Hong Kong (2015; pp. 1-15) https://www.nchk.org.hk/filemanager/en/pdf/conduct.pdf Kenya: National Nurses Association of Kenya (NNAK), Code of Conduct and Ethics (2009; pp. 120) https://eacc.go.ke/default/wp-content/uploads/2018/08/nnak-code.pdf

Sultanate of Oman: Ministry of Health, Principles of Code of Professional Conduct for Nurses in the Sultanate of Oman (2019; $\quad$ pp. $1-41)$ https://www.moh.gov.om/documents/106926/2918442/Principles+of+Code+of+Professional +Conduct+for+Nurses+in+the+Sultanate+of+Oman/d452d811-c765-473b-90b7-66d4761a028d

United Arab Emirates (UAE): Nursing and Midwifery Council, Nursing and Midwifery Code of Conduct (2013; pp. 1-17) http://www.uaenmc.gov.ae/Data/Files/Code\%20of\%20Conduct.pdf

United Kingdom (UK): Nursing and Midwifery Council, The Code (2015; online)

https://www.nmc.org.uk/standards/code/read-the-code-online

United States of America (USA): American Nurses Association (ANA), Code of Ethics (2015; pp. $1-48)$

https://www.nursingworld.org/practice-policy/nursingexcellence/ethics/\#: : text=The $\% 20$ American $\% 20$ Nurses $\% 20$ Association $\% 20$ (ANA) $\% 20$ Center \%20for\%20Ethics, rights\%20at\%20the \%20state,\%20national,\%20and\%20international $\% 201$ evels

\section{International Year of the Nurse and the Midwife Campaign 2020}

Together, nurses and midwives represent almost a $1 / 4$ billion health care providers worldwide. To honour the important contributions of these professional carers, the World Health Organization designated the year 2020 as the International Year of the Nurse and the Midwife. This coincides with the $200^{\text {th }}$ anniversary of Florence Nightingale's birthday. Known as the 'lady with the lamp' during the Crimean war, Nightingale was a nursing pioneer and leader whose thoughts and actions were far ahead of her time. Nightingale stood for "the value of stories, sensitivity, solidarity, space, scholarship and sustainability" [5]. These key concepts are still integral to the work of contemporary nurses who are committed to improving patient health outcomes, facilitating familyinvolved care, and integrating evidence-informed, best practices.

It is ironic that the International Year of the Nurse and the Midwife should coincide with the start of the COVID-19 pandemic. Further, the opportunity to reflect on the historical role of a nursing icon can offer (perhaps unexpectedly) important strategic priorities for nursing that have not changed very much over two centuries. Nurses still ought to seek the stories of patients, families, and interdisciplinary members of the health care team. Stories are an invaluable source of knowledge and understanding that can improve ethical decision-making, contextualize responsiveness, and contribute to better quality of care. Care interventions ought to be appropriate for the individual and their circumstances and delivered in compassionate ways (even during a global health crisis), with a sensitivity to contextual needs and factors. As nurses, we ought to serve in solidarity with each other and as key stakeholders in the health care organizations and systems that we are an integral part of. In the spaces and places that nurses work and live, we must promote and protect health, well-being, and safety for individuals and communities. Finally, scholarship and sustainability are ongoing commitments that nurses ought to continue to assertively pursue, as experts with unique knowledge and perspectives to creatively respond to our most difficult issues. This can only be attained if nurses speak up and speak out, not only in the contexts of courage, resilience, and hope, but also to boldly acknowledge and identify the harsh realities and sources of amenable suffering. In 2020, we were reminded about the many important historical contributions by Florence Nightingale, nurses, and midwives. Moving forward, let us not forget all that nurses and midwifes have to offer toward our combined efforts to achieve better health outcomes in our shared global village.

During the COVID-19 pandemic, a panel of global nurse leaders gathered in August of 2020 to participate in two international webinars (\#18- https://www.youtube.com/watch?v=a6OGi- 
1qZFk ; and, \#19- https://www.youtube.com/watch?v=ieBxXj3eqWQ) hosted by the Education Department of the UNESCO Chair in Bioethics. The title for the sessions was "Medical ethics in the wake of the COVID pandemic: International panel discussion- Nurses, bioethics, and the response to the COVID-19 pandemic." Specifically, the global nurse leaders were tasked to address Article 13- Solidarity and cooperation. The panelists discussed their experiences and extraordinary challenges with COVID-19 in the context of their own countries and contexts, across 10 different nations. Shared goals, common experiences, and significant differences were identified and explored. From the fulsome panel discussions that occurred during the webinars, a manuscript was prepared and published in the international academic journal of the UNESCO Chair in Bioethics:

Jones-Bonofiglio, K., Arulappan, J., Brown, A., Cassells, K., Cooper, V., DiGangi Condon, K., Gurevich-Gal, R., Jeyasingh, R.C., Kalaimathi, S.A., Kezia, J.R., Leung, S., Titus, S., Neumann, J., \& Atieno Wagoro, M.C. (2020, Dec) 'We are all in this together': Nurses and ethical issues during the COVID-19 pandemic. Global Bioethics Enquiry, 8(3), 177-181. https://globalbioethicsenquiry.com/wp-content/uploads/2021/02/VP2-NURSING-1.pdf

Therefore, members of the panel of global nurse leaders had opportunities to participate in global social witnessing through acts of solidarity and cooperation, by coming together as a community of nursing practice for the webinar series and through ongoing collaborative work to produce a publication. Global social witnessing allows for mindful attention and embodied awareness of global events, such as the COVID-19 pandemic. Such collective and individual social witnessing brings a shift from linear mental processing to an active compassionate response from mind, heart, and body (The Pocket Project, n.d.).

\section{Purpose}

The purpose of this document is to present a call to action and propose international health care ethics policy guideline recommendations in response to the COVID-19 pandemic from a global nursing perspective, in the context of UNESCO's Declaration. Specifically, these recommendations will follow the Declaration's Application of the Principles, namely:

- Article 18- Decision-making and addressing bioethical issues

- Article 19- Ethics committees

- Article 20- Risk assessment and management

- Article 21- Transnational practices

\section{UNESCO's Chair in Bioethics Education Department's Global Nurse Leaders Panel: A Call to Action}

The value of nurses has been recognized as essential during the coronavirus/COVID-19 pandemic. However, the value of nurses has not been upheld within global health care systems during this recent and ongoing crisis. Experiences of nurses during the pandemic indicate extreme psychological distress (e.g., fear, anxiety, grief, powerlessness, desperation, despair), stigma, inadequate access to personal protective equipment (PPE), unsafe infection control protocols, delayed testing and reporting, erratic messaging, understaffing, and reduced trust in employers, health care organizations, and governments [6]. Accurate numbers are not yet available to discern how many nurses' lives have been lost to the SARS-CoV-2 virus.

Members of the panel of global nurse leaders, which represents 14 individuals and 10 nations around the world, calls on governments, health care organizations, and other stakeholders to renew their commitments to more fully value and directly support nurses and their essential work with interdisciplinary teams across diverse health care practice settings. 
The important contributions of nurses in our world's health care systems have defined nurses as much needed partners and key stakeholders in global health, both during crisis and beyond. As such, the panel members recommend the following call to action to be immediately implemented and to continue in an ongoing basis:

- Protect and promote the physical and mental health, well-being, and safety of nurses working in various health care areas/environments around the world.

- Recognize nurses as key stakeholders with the need for equal partnerships in local, national and global health care domains.

- Support leadership opportunities, continuing ethics education, and leadership training/development for nurses in various roles with organized efforts to garner nurses' engagement and meaningful consultation on direct and indirect matters of patient and family care, community and public health, and health policy/legislation development.

- Increase the number of nurses in formally designated leadership positions with decision-making power in health care organizations and government, especially those roles traditionally and exclusively held by medical doctors only.

Additional Calls to Action for Consideration:

American Nurses Association call to action report:

https://www.nursingworld.org/ 4907b6/globalassets/docs/ana/ana-call-to-action--exploringmoral-resilience-final.pdf

American nurses call to action: https://www.aacn.org/ /media/aacn-website/policy-andadvocacy/the-fight-against-covid-19-joint-statement-4-10-20.pdf?la=en

ICN call to action: https://www.icn.ch/system/files/documents/2020-

04/ICN\%20briefing_COVID19_Top_priorities_ENG.pdf

Immigrant nurses call to action (Philippines/Pakistan):

https://onlinelibrary.wiley.com/doi/10.1111/jan.14432

Public health nurses call to action (USA):

https://onlinelibrary.wiley.com/doi/full/10.1111/phn.12733

WHO call to action: https://www.who.int/campaigns/world-aids-day/2020/key-messages

\section{UNESCO's Chair in Bioethics Education Department's \\ Global Nurse Leaders Panel: \\ International Health Care Ethics Guideline Recommendations}

\section{Article 18- Decision-making and addressing bioethical issues}

Ethical decision-making can be promoted and enhanced through activities that support nurses to uphold their obligations (duty of care) as professionals and their personal moral values as individuals and community members. Ethical issues in practice can be addressed with appropriate knowledge sharing and ongoing, engaged dialogue with stakeholders who represent diverse perspectives. As key stakeholders in health care systems globally, nurses must be included in all levels of planning and protocol development, including stewardship and allocation of resources. Even in crisis conditions, such as the COVID-19 pandemic, nurses must not be excluded from ethical decision-making activities.

\section{Article 19- Ethics committees}

Ethics committees in various health care settings support and guide research, clinical decision making, policy development, and/or ethics education and awareness. Within these important roles and responsibilities is the need for the voices of nurses, as the largest component of the global health care workforce and a vital part of the multidisciplinary cohort, in partnership with the organization and in alignment with essential mission, vision, and values statements. Even in crisis conditions, such as the COVID-19 pandemic, ethics committees must continue to be judiciously utilized to make evidence-informed decisions on protocols, policies, and practices. 


\section{Article 20- Risk assessment and management}

Assessment, management, and mitigation of risk in various health care settings requires access to up-to-date, comprehensive, and timely information that is delivered via multiple modalities for communication. Risk must be assessed for all individuals within the health care setting including frontline care providers, administrative staff, management, senior leadership, patients, families/caregivers, and the community. Reasonable expectations for health protection and promotion of the many must be measured against legal and human rights of individuals, and through a lens of equity. Communication strategies must seek ongoing collaboration and coordination among and between health care organizations, public health, communities, and nations. Frontline nurses and other health care worker personnel must have their concerns about safety, protection, and adequate support addressed.

\section{Article 21- Transnational practices}

Transnational practices, in the context of the Declaration, largely refers to research endeavours and appropriate ethical and/or legal review and oversight. Within research endeavours, there are opportunities for much needed reciprocity through systematic and global approaches to facilitating data gathering, access, sharing, and utilization that may provide important and responsive benefits to urgent global health issues. Further national nursing organizations should have an engaged role in supporting research contributions, promoting education, and facilitating the uptake and utilization of evidence-informed findings, engaging all members across all health care sectors to respond in solidarity and cooperation. Such actions recognize and value the importance of the global efforts of nurses as a world-wide community of practice and enhance much needed access to quality information to inform decision-making.

\section{Appendix A}

\section{Recommended Readings}

1. Canadian Nurses Association (2020). Nurses' ethical considerations during a pandemic. https://cnaaiic.ca/-/media/cna/covid-19/nurses-ethical-considerations-during-a-pandemic_e.pdf

2. Berlinger, N., Wynia, M., Powell, T., Hester, D. M., Milliken, A., Fabi, R., \& Jenks, N. P. (2020). Ethical framework for health care institutions responding to novel Coronavirus SARS-CoV-2 (COVID-19) guidelines for institutional ethics services responding to COVID-19. The Hastings Center, 12 . https://www.mentice.com/hubfs/COVID-19/White\%20paper\%202020\%20\%20Hastings\%20Center\%20COVID\%20Ethical\%20Framework.pdf

3. Bursztajn H, \& Levy-Carrick N. (2020, Dec 21). A pandemic of false choices. Psychiatric Times. https://www.psychiatrictimes.com/view/a-pandemic-of-false-choices

4. Hamilton, D. \& Gallagher, A. (2020, Apr 16). COVID-19: nursing in a pandemic and how to apply ethical decision-making in practice. https://rcni.com/nursing-standard/opinion/comment/covid19-nursing-a-pandemic-and-how-to-apply-ethical-decision-making-practice-159996

5. Huang, L., Lin, G., Tang, L., Yu, L., \& Zhou, Z. (2020). Special attention to nurses' protection $\begin{array}{lllll}\text { during the COVID-19 epidemic. Critical Care, } 24, & \end{array}$ https://ccforum.biomedcentral.com/articles/10.1186/s13054-020-2841-7

6. International Council of Nurses. (2020, Sept 14). Protecting nurses from COVID-19 a top priority: A survey of ICN's national nursing associations. Author. https://www.icn.ch/system/files/documents/2020-09/Analysis COVID19\%20survey\%20feedback 14.09.2020\%20EMBARGOED\%20VERSION 0.pdf

7. Kreh, A., Brancaleoni, R., Magalini, S. C., Chieffo, D. P. R., Flad, B., Ellebrecht, N., \& Juen, B. (2020). Ethical and Psychosocial considerations for hospital personnel in the COVID-19 crisis: Moral Injury and Resilience. MedRxiv. https://www.medrxiv.org/content/10.1101/2020.11.18.20232272v1.full

8. Jones-Bonofiglio K. (2020). Health care ethics through the lens of moral distress. Springer.

9. McGuire, A. L., Aulisio, M. P., Davis, F. D., Erwin, C., Harter, T. D., Jagsi, R., ... \& COVID-19 Task Force of the Association of Bioethics Program Directors (ABPD). (2020). Ethical challenges arising in the COVID-19 pandemic: An overview from the Association of Bioethics Program Directors (ABPD) task force. The American Journal of Bioethics, 20(7), 15-27. 
10. Monforte-Royo, C., \& Fuster, P. (2020). Coronials: Nurses who graduated during the COVID-19 pandemic. Will they be better nurses? Nurse Education Today. https://www.ncbi.nlm.nih.gov/pmc/articles/PMC7387935/

11. Phelps, A. and Lawrence-Wood, E. (2020). The morals and ethics of the COVID-19 frontline. Health \& Wellbeing. https://pursuit.unimelb.edu.au/articles/the-morals-and-ethics-of-the-covid-19frontline

12. Shakya, D. R. (2020). Stress management-A way ahead. Journal of BP Koirala Institute of Health Sciences, 3(1), 1-8. https://www.researchgate.net/publication/343239323_Stress_ManagementA_Way_Ahead

13. Shakya, D. R., Mishra, D. R., Gyawali, R., Rimal, S. P., Lama, S., Yadav, A. K., ... \& Sapkota, N. (2020). COVID-19 Pandemic and BPKIHS: our situation, endeavors and future direction. Journal of BP Koirala Institute of Health Sciences, 3(1), 39-49. https://www.researchgate.net/publication/343239404 COVID-

19 Pandemic and BPKIHS our_Situation_Endeavors and Future Direction

14. The SARS Commission. (2006). Executive summary: Spring of fear (volume 1). http://www.archives.gov.on.ca/en/e_records/sars/report/v1.html

15. Ulrich, C. M., Rushton, C. H., \& Grady, C. (2020). Nurses confronting the coronavirus: Challenges met and lessons learned to date. Nursing Outlook, 68(6), 838-844. https://www.sciencedirect.com/science/article/pii/S002965542030659X?casa token=9mwJrpc5 BOYAAAAA:Lldv7pRKMQTkXCQwzMYB84HR3fMNMu_Lhsg7fACZDsSrhepBS5kSt9Vuc8IpDd5P12s-kSg4Go

16. Vahidy, F. S., Bernard, D. W., Boom, M. L., Drews, A. L., Christensen, P., Finkelstein, J., \& Schwartz, R. L. (2020). Prevalence of SARS-CoV-2 infection among asymptomatic health care workers in the greater Houston, Texas, area. JAMA Network Open, 3(7), e2016451-e2016451. https://jamanetwork.com/journals/jamanetworkopen/fullarticle/2768707

17. Wagoro, M. C. A., Omondi, E.A , Cheptum, J.J., Munoru, F.M. \&Nyansikera, R. (2020). Nursing patients with COVID-19 in Kenya: Balancing duty of care and fear. Journal of Association of Kenyan $\begin{array}{llll}\text { Physicians, } & \text { S14, } & 3(2), & \text { s10- }\end{array}$ https://www.researchgate.net/publication/341775142 Nursing Patients with COVID19 in Kenya Balancing Duty to_Care and Fear

18. World Health Organization, International Council of Nurses, \& Nursing Now. (2020). State of the world's nursing 2020: Investing in education, jobs, and leadership. World Health Organization. https://www.who.int/publications/i/item/9789240003279

19. World Health Organization. (2020, Sept 17). Charter. Health workers safety: a priority for patient safety. Author. https://www.who.int/docs/default-source/world-patient-safety-day/healthworker-safety-charter-wpsd-17-september-2020-3-1.pdf

20. Wright, D. K., Peterson, W., \& Gifford, W. (n.d.). Nurses ethical considerations during a pandemic. Canadian Nurses Association. https://cna-aiic.ca/-/media/cna/covid-19/nurses-ethicalconsiderations-during-a-pandemic_e.pdf

\section{REFERENCES}

1. Wagoro MCA, Omondi EA, Cheptum JJ, Munoru FM, Nyansikera R. Nursing patients with COVID-19 in Kenya: Balancing duty of care and fear. J Assoc Kenyan Physicians 2020;3(2):s10-7.

2. Edmonds JK, Kneipp SM, Campbell L. A call to action for public health nurses during the COVID19 pandemic. Pub Health Nurs 2020;37:232-4.

3. Stievano A, Tschudin V. The ICN code of ethics for nurses: a time for revision. Int Nurs Rev 2019;66(2):154-6.

4. International Council of Nurses (ICN). (2012). The ICN code of ethics for nurses. https://www.icn.ch/sites/default/files/inline-les/2012_ICN_Codeofethicsfornurses_\%20eng.pdf

5. Gallagher A. Learning from Florence Nightingale: A slow ethics approach to nursing during the pandemic. Nurs Inquiry 2020;27(3):e12369.

6. Brophy JT, Keith MM, Hurley M, McArthur JE. Sacrificed: Ontario healthcare workers in the time of COVID-19. New Solutions: A Journal of Environmental and Occupational Health Policy 2021;30(4):267-81.

7. Jones-Bonofiglio K, Arulappan J, Brown A, Cassells K, Cooper V, DiGangi Condon K, GurevichGal R, Jeyasingh RC, Kalaimathi SA, Kezia JR, Leung S, Titus S, Neumann J, Atieno Wagoro MC. We are all in this together': Nurses and ethical issues during the COVID-19 pandemic. Global Bioethics Enquiry 2020;8(3):177-81. 
8. Gallup Politics. https://news.gallup.com/poll/328136/ethics-ratings-rise-medical-workersteachers.aspx

9. The Pocket Project. (n.d.). Global social witnessing. https://pocketproject.org/global-socialwitnessing/?inf_contact_key=0a2a694a2ad63780e8c38c999156cb5acc0558ed5d4c28cbfab114022b 1 ec50d

10. United Nations Educational Scientific and Cultural Organization (UNESCO). (2005). Universal declaration of bioethics and human rights. https://unesdoc.unesco.org/ark:/48223/pf0000142825.page $=80$

Acknowledgements: Nil

Funding: Nil

Conflict of interest: Nil 